\title{
The Legitimacy of User Knowledge in Decision-Making Processes in Mental Health Care: An Analysis of Epistemic Injustice
}

\author{
Katarina Grim $(\mathbb{D} \cdot$ Malin Tistad $\cdot$ Ulla-Karin Schön $\cdot$ David Rosenberg
}

Received: 4 June 2019/Accepted: 5 August 2019/Published online: 16 August 2019

(C) The Author(s) 2019

\begin{abstract}
The experience-based knowledge of users is considered to provide vital input in shared decision making (SDM). However, mental health service users frequently express having negative experiences from meetings with providers, which are of an epistemic nature (e.g., being ignored or not regarded as credible). This study aimed to explore the barriers involved in legitimizing user knowledge in decision-making processes. Interview data from service users and providers were viewed from a theoretic framework of epistemic injustice. Abductive content analysis was conducted on data collected during a project to develop and implement SDM in mental health services. In describing obstacles to legitimize user knowledge, service users highlighted relational issues: being dependent, often dismissed and choosing to edit
\end{abstract}

K. Grim · M. Tistad · U.-K. Schön

School of Education, Health and Social Studies, Dalarna University, Falun, Sweden

U.-K. Schön

Department of Social Work, Stockholm University, Stockholm, Sweden

D. Rosenberg

Department of Social Work, Umeå University, Umeå, Sweden

\section{K. Grim $(\bowtie)$}

Department for Psychological and Social Studies, Karlstad University, 65188 Karlstad, Sweden e-mail: katarina.grim@kau.se their testimonies. Service providers typically described workflow issues, users' insufficient decision-making competence and users' vulnerability to stress factors. The findings suggest that greater epistemic justice might be achieved by a SDM process in which the service user is engaged as a full partner in collaboration in various activities related to their care.

Keywords Mental health services - Shared decision making (SDM) - User knowledge · Epistemic injustice

\section{Introduction}

In the past few years we have seen increased attention paid to service users' competence and role in contributing to decisions regarding their own care and support [1]. Shared decision making (SDM) has been promoted as a practice to ensure that people receive care and support corresponding to individual circumstances and choices [1]. In SDM information is shared mutually and joint decisions are made in a process by which service users and providers are conceptualized as equally valuable carriers of knowledge [2]. However, research on SDM within a mental health context shows how the value placed on personal knowledge of service users often remains low [3] and that service users perceive that the extent to which their 
knowledge is considered in decision making is comparatively limited [2-4]. Individuals with mental health problems frequently express having negative experiences from meetings with service providers, which may conceived to be of an epistemic nature. They report instances of not being listened to, of not being taken seriously or of not being regarded as credible due to their psychiatric condition.

Several aspects of the context of mental health care have been identified that differ from other health care contexts and which influence service users' possibilities to be active partners in epistemic efforts of problem analysis and decision making. It is suggested that providers often underestimate the service users' insight and capacity for decision making, and that this may exaggerate imbalances between user knowledge relative to the knowledge base of professionals [3]. Advocates of social/holistic conceptions of mental illness relate such imbalances to the prevalent dominance of biomedical models, which might obscure alternative explanations [3] and minimize important personal knowledge relating to contextual and social conditions [5].

Creating conditions whereby the knowledge of service users is legitimized in deliberation processes is considered crucial [6, 7]. Some investigators underscore that practice and methods development that adequately target obstacles for genuine partnership in SDM need to be preceded by a clearer understanding of the mechanisms at work in the domains of epistemology, role expectations and power $[4,8]$.

In the present study, data generated from interviews with service providers were juxtaposed with those of service users and viewed through the lens of epistemic theory, with the aim of exploring how these groups perceive the nature and value of user knowledge and their descriptions of obstacles to making full use of user knowledge in decision-making processes. By applying a conceptual framework of epistemic injustice to these inquiries the study seeks to analyze specific barriers involved in legitimizing user knowledge in decision making that are currently poorly understood and that warrant further attention in future efforts aimed at increasing user participation. Gaining insight into the specifics of the dynamics at work and how they are experienced by service users might raise the awareness of practitioners in their interactions with service users and endorse sustainable changes of practice wherein genuine partnership and a greater epistemological justice in decision-making processes are achieved.

Applying an 'injustice framework' to empirical data might involve value-laden presumptions of injustices that could bias the analysis. However, because the epistemic disadvantages of service users were consistently reflected in the present data and were described as key barriers to the implementation of SDM [3, 4, 7], this framework was chosen to study the dynamics involved in epistemic interactions from the perspective of epistemic challenges and imbalances.

\section{Epistemic Injustice}

Recent studies that have drawn attention to the epistemic aspects of the complexities involved in accessing and actively making use of user knowledge in the context of mental health care suggest that they can be brought to light most effectively by using Fricker's [9] conception of epistemic injustice $[6,10,11]$.

The concept of epistemic injustice refers to an injustice done to individuals in their capacity as knowledge bearers, reasoners and questioners, in which their ability to take part in epistemic practices, such as giving knowledge to others (testifying) or making sense of their experiences (interpreting), is weakened $[9,10]$. As the description suggests, Fricker identifies two such wrongs: testimonial injustice and hermeneutical injustice. Testimonial injustice is the injustice a speaker suffers when a hearer assigns an unwarranted level of credibility to his or her testimony. This devalued credibility is often due to identity prejudice. The speakers' membership in a negatively stereotyped group causes the hearer to view their accounts and arguments as less competent and sincere and thus less trustworthy. Hermeneutical injustice occurs when there is a breach in shared conceptual, interpretative resources that puts individuals at a disadvantage when trying to make sense of their experiences. When shared modes of interpretation (such as concepts, ideas and narratives) are absent or not fairly accessible, these individuals are deprived of the capacity to use and develop the shared descriptive labels necessary for mutual understanding of the 
phenomena they experience [9]. In recent years many theorists have expanded on the theory of epistemic injustice [12-14]. One such elaboration of relevance for the present analysis is the concept of participantbased injustice [13]. This concept describes how being an equal communicator requires not only that a person's accounts are assessed with due credibility, but also that the person is acknowledged as a "contributor in knowledge-gathering practice" and a capable "collaborator in shared inquiry, ... as someone who can ask pertinent questions and recognize relevant information in problem-solving inquiries" [15, p 339].

Reportedly, these conceptualizations characterize many attitudes mental health service users encounter when voicing their opinions about their care, convey experiences or state priorities and preferences [10]. For several reasons, people with mental health problems are susceptible to epistemic injustice, including cognitive and social disadvantages, persistent negative stereotypes and the higher value placed on 'hard' or objective evidence as compared with service user selfreports [10, p 67].

\section{Method}

\section{Background of the Current Study}

The data for this study are derived from the qualitative phases of a multi-phase project performed between 2014 and 2016. The aim of the project was to develop a supportive structure for SDM in the form of a decision support tool (DST) and supporting the implementation of SDM in the context of the Swedish mental healthcare system [16-18]. During the development and implementation of SDM, it became evident that the possibilities for user knowledge to be expressed and validated in the kind of joint deliberation that SDM requires were associated with several difficulties. Qualitative data collected through individual and focus group interviews with service users and service providers (separately) proved to be a rich in statements reflecting the insufficiencies and challenges related to full epistemic partnership of SDM, and which is commonly considered an important topic for further inquiry [7, 10, 19]. Hence, these sets of data were perceived to be suitable for an analysis in accordance with the aim of this study.
Data and Participants

Throughout the multi-phase project (of developing, testing and implementing the DST), a large body of data were collected through focus group and individual interviews conducted at different stages and with diverse purposes during this process. For this study, excerpts from the transcriptions that were found to relate to the epistemic domain were extracted from these data sets to form the empirical basis for the present analysis. In these passages, service users and providers relate their experiences, attitudes and preconditions in relation to valuing and sharing knowledge. In all stages of data collection the questions in the interview guides were mainly problem-oriented, i.e. the questions focused on instances when shared decision processes were difficult, what kinds of information is needed and what needs of support arise in such cases and how decision support may be designed in response to those difficulties and needs.

When extracting these excerpts from the total body of data generated in the project, most comments were from service users because interviews with providers predominantly targeted other aspects of implementation (e.g., contextual determinants and technical issues). The data sets selected for the present analysis from previous studies are outlined in Table 1. Full descriptions of the settings, purpose and methods of data collection and analysis of the data sets are provided in these studies. Experiences and views from service users were primarily collected in the first two phases $[16,18]$ and service provider perspectives were mostly collected during the third phase [17].

The majority of the service users were members of user panels. These individuals had received training in basic research techniques and how to consult with researchers on projects to contribute with a user perspective.

\section{Data Analysis}

All interviews were recorded and transcribed verbatim throughout the multi-phase project. All data were analyzed using qualitative content analysis. The data had been approached from different perspectives to examine the various stages of developing and implementing support for SDM. In this study the data were approached from a theory-driven perspective on epistemic injustice. To avoid formulating categories 
Table 1 Project phases of developing and implementing support for SDM

\begin{tabular}{|c|c|c|c|}
\hline Project phase & Participants & Data collection & Settings \\
\hline $\begin{array}{l}\text { Explorative } \\
\text { phase }\end{array}$ & $\begin{array}{l}\text { Adults with } \\
\text { experiences of } \\
\text { psychiatric care } \\
\mathrm{N}=22 *\end{array}$ & $\begin{array}{l}\text { Three focus group interviews with service } \\
\text { users were conducted with a semi- } \\
\text { structured interview guide focusing on } \\
\text { information priorities and needs for support } \\
\text { in decision-making processes }\end{array}$ & $\begin{array}{l}\text { User panels linked to social work programs at } \\
\text { two universities at different sites in } \\
\text { Sweden-1st and } 2 \text { nd focus group } \\
\text { interview } \\
\text { Community-based activity service in a mid- } \\
\text { size town in Sweden }\end{array}$ \\
\hline $\begin{array}{l}\text { Development } \\
\text { and design } \\
\text { phase }\end{array}$ & $\begin{array}{l}\text { Person with } \\
\text { experiences of } \\
\text { psychiatric care } \\
\text { Specialist } \\
\text { psychiatric care } \\
\text { counselor } \\
\text { Community } \\
\text { psychiatric } \\
\text { service } \\
\text { coordinator }\end{array}$ & $\begin{array}{l}\text { Three individual interviews conducted with } \\
\text { semi-structured interview guide focusing } \\
\text { on usability and feasibility of a decision } \\
\text { support tool (DST) prototype }\end{array}$ & $\begin{array}{l}\text { Service design company in a larger town in } \\
\text { Sweden }\end{array}$ \\
\hline $\begin{array}{l}\text { Implementation } \\
\text { and evaluation } \\
\text { phase }\end{array}$ & $\begin{array}{l}\text { Staff }(n=29) \\
\text { Occupation: } \\
\text { Nurse }=5 \\
\text { Case } \\
\text { manager }=10 \\
\text { Psychiatrist }=1 \\
\text { Psychologist = } 4 \\
\text { Care/community } \\
\text { Support } \\
\text { worker }=9\end{array}$ & $\begin{array}{l}\text { Four semi-structured focus group interviews } \\
\text { with service providers using a semi- } \\
\text { structured interview guide assessing } \\
\text { experiences of the implementation } \\
\text { activities and the use of the DST, as well as } \\
\text { on mapping barriers and facilitators for } \\
\text { implementation of SDM }\end{array}$ & $\begin{array}{l}\text { Six units in four municipalities in Sweden } \\
\text { Two municipal social services offering } \\
\text { residential support and case management } \\
\text { (urban areas) } \\
\text { Four outpatient psychiatric services offering } \\
\text { medical treatment, therapy and home visits } \\
\text { (two from urban and two from rural areas) }\end{array}$ \\
\hline
\end{tabular}

*Among these 22 persons, 2 also had the perspective as a relative to a service user

based exclusively on existing theory an abductive content analysis was applied, incorporating both inductive and deductive approaches in the different stages of the analysis [20].

In a first step literature on epistemic injustice was reviewed, a process during which it became clear the framework presented by Fricker [9], together with modifications from more recent literature, could provide orienteering concepts to serve in the analytic perception to relevant issues, processes and interpretations [21]. Next, selected transcripts were read several times to get a sense of the whole. Words and phrases related to knowledge sharing and knowledge valuation in decision-making processes were marked to form preliminary codes [22]. The codes were compared based on differences and similarities and sorted into preliminary categories. Next, followed a period of shifting back and forth between data and theory and viewing them in light of each other. Concepts from the theory were found to contribute to the identification and naming of additional codes and in the clustering of codes [20]. The three forms of epistemic injustice previously described were chosen to provide a basis for the deductive analysis (Table 2). An unconstrained matrix was constructed to allow categories to be created within its bounds, that were not established directly from theoretical concepts [23] but where theoretical concepts guided the discovery of categories and contributed to the naming of some, but not all categories. In a last review of all data some codes were renamed and some rearranged in correspondence with the finalized matrix. 
Table 2 Main categories, categories and examples of codes

\begin{tabular}{|c|c|c|}
\hline Main category & Category & Examples of codes \\
\hline \multirow[t]{14}{*}{ Testimonial injustice } & \multicolumn{2}{|l|}{ User perspectives } \\
\hline & \multirow[t]{3}{*}{ Being devalued as testifiers } & Not being believed \\
\hline & & Being ignored \\
\hline & & $\begin{array}{l}\text { Having experiential knowledge } \\
\text { unacknowledged }\end{array}$ \\
\hline & \multirow[t]{3}{*}{ Perceiving communication as a struggle } & Prestigiousness of providers \\
\hline & & Bringing'witness' \\
\hline & & 'Battle' and'defense'-metaphors \\
\hline & \multirow[t]{3}{*}{ Being silent or editing testimonies } & Feeling it is useless to speak \\
\hline & & Fear of negative consequences \\
\hline & & $\begin{array}{l}\text { Insecurity when confronting } \\
\text { authority }\end{array}$ \\
\hline & \multicolumn{2}{|l|}{ Staff perspectives } \\
\hline & $\begin{array}{l}\text { Service users being silent or editing } \\
\text { testimonies }\end{array}$ & $\begin{array}{l}\text { Insecurity when confronting } \\
\text { authority }\end{array}$ \\
\hline & & Being unaccustomed to participate \\
\hline & & Lack of capacity or willingness \\
\hline \multirow{8}{*}{$\begin{array}{l}\text { Participant-based injustice-not inviting/being } \\
\text { invited as a collaborator }\end{array}$} & \multicolumn{2}{|l|}{ User perspectives } \\
\hline & \multirow{3}{*}{$\begin{array}{l}\text { Being disregarded as epistemic } \\
\text { collaborators }\end{array}$} & Not invited to problem analysis \\
\hline & & Excluded from decision making \\
\hline & & $\begin{array}{l}\text { Being discouraged from information } \\
\text { gathering practices }\end{array}$ \\
\hline & \multicolumn{2}{|l|}{ Staff perspectives } \\
\hline & \multirow[t]{3}{*}{$\begin{array}{l}\text { Disinclination to involve service users in } \\
\text { collaborative practice }\end{array}$} & $\begin{array}{l}\text { Protecting service users from self- } \\
\text { destructive choices }\end{array}$ \\
\hline & & $\begin{array}{l}\text { Safeguarding service users from } \\
\text { information overload }\end{array}$ \\
\hline & & $\begin{array}{l}\text { Being advocates in navigating } \\
\text { unwieldy systems }\end{array}$ \\
\hline \multirow[t]{14}{*}{ Hermeneutical injustice } & \multicolumn{2}{|l|}{ User perspectives } \\
\hline & \multirow{3}{*}{$\begin{array}{l}\text { Poorly fitting formats for narratives and } \\
\text { interpretations }\end{array}$} & Not enough time \\
\hline & & Fragmented systems \\
\hline & & The lens of medicalization \\
\hline & \multirow[t]{3}{*}{ Lack of control over interpretations } & No control over documentation \\
\hline & & Behavior being psychiatrized \\
\hline & & $\begin{array}{l}\text { Providers' lack of recovery } \\
\text { knowledge }\end{array}$ \\
\hline & \multirow[t]{3}{*}{ Not accessing hermeneutical resources } & Bureaucratic language \\
\hline & & Hard to understand experiences \\
\hline & & Medical terminology \\
\hline & Staff perspectives & \\
\hline & \multirow[t]{3}{*}{ Restricted outlets for narratives } & Time limitations \\
\hline & & Fragmented systems \\
\hline & & $\begin{array}{l}\text { Service users' difficulties in } \\
\text { expressing themselves }\end{array}$ \\
\hline
\end{tabular}




\section{Findings}

A crosscutting theme throughout the data was service users' vulnerability to epistemic challenges (e.g., not believed or not taken seriously and not able to access medical terminology). In comments relating to obstacles for making use of user knowledge in decisionmaking processes the two groups (providers and service users) reported both overlapping and distinctive phenomena. Some of the same issues noted by both groups were understood differently.

When examining their comments from the framework of epistemic injustice, epistemic phenomena could be discerned to explain this discrepancy of perceptions regarding the premises for user knowledge to be expressed and validated in decision-making processes. In the following analysis identified mechanisms of epistemic injustice are reported as is the ways in which they affect service users' willingness to speak candidly and to collaborate in the manner they would prefer.

The participants listed in Table 1 are regarded as being representative of the categories presented in Table 2 and are identified as follows: service users (SU1-SU23), providers (P1-P31).

\section{Testimonial Injustice}

\section{Being Devalued as Testifiers: User Perspectives}

Service users described how they were often assigned characteristics that demoted the credibility of their testimonies. The category Being devalued as testifiers involves service users' experiences of having their accounts met with incredulity or disinterest. Service users referred to different kinds of information that they wanted to have considered in the decisionmaking processes. Some expressed how they were active knowledge seekers, often consulting external sources (e.g., the Internet and peers). Several service users who had a long history of living with illness and had developed strategies for self-help and coping expressed that such knowledge might be relevant to consider when choosing among interventions options. However, service users reported feeling inferior and as lacking judgment and decision-making capacity owing to their psychiatric condition. Many reported that their descriptions of their problems were often doubted or ignored. For example, some noted how providers' knowledge of previous periods of psychosis predisposed the providers to disregard their suggestions. One service user describes this attitude as, "Because you have had psychosis you probably don't know your own good" (SU8). Others mentioned how their mental health problem led service providers to ignore them. As one user commented, "After they found out about my diagnosis, then in their eyes I no longer existed" (SU15).

An adjacent category involves perceiving соттиnication as struggles-user perspectives. This category contains comments indicating that communicating ideas and information entail a struggle from a disadvantage. The experience of being dependent and exposed was, for example, reflected in service users' desire to include some sort of neutral (SU5) person to meetings that could serve as a witness (SU6) and in discussions on whether it was legally permissible to audio record meetings. It was noted how bringing a relative or friend with professional status into the consultation room resulted in the providers showing greater respect and becoming more attentive. Descriptions of meetings and preparation of meetings with providers were rich in metaphors related to battle and defense. One service user remarked that service users should have the same opportunity as the staff to prepare before meetings, “...so you can mobilize your own forces. I bring aunt $\mathrm{XX}$, who has previously worked in psychiatry ...Or anything, just so that you have your artillery" (SU3).

In relation to these expressions of struggle in interactions, the prestigiousness of the providers was often described as a barrier for user knowledge to be recognized in decision-making processes. One service user noted:

If you could tear down the walls about the practitioners' view of themselves as experts and as the ones who have the knowledge, you would come very far. We are the ones who have expert knowledge of ourselves, but that knowledge is rarely considered. Instead, everything is expressed as diagnostics and there is a lot of prestige (SU2).

A prerequisite for a dialogue on more equal terms was noted to be that providers relate to service users as "equal human beings" (SU4) and be conscious of the power differentials embedded in the interactions. Such awareness was, however, noted as radically limited. 
One person noted that providers might "think they do shared decision making" and reflected that providers and service users may have "different perceptions of what it means" (SU4). Another user stated that the "foundation of all decision-making is that one is treated as a worthy person, as a fellow human being" and that practitioners "always have to be aware that you sit in a position of power and that you are not abusing it. ... They must be aware of that. But they are not" (SU1).

\section{Being Silent or Editing of Testimonies: User Perspectives}

This category involves comments relating to service users suppressing their expressions to adapt to the structures and attitudes underpinning mental health care practice. Staying silent or editing the communication due to imbalances of power was often stated by service users.

Based on previous negative experiences, some service users chose to remain silent because they felt that it was futile to inject their input and preferences. Other users described how they modified their communication to increase the likelihood to be listened to, or for fear of being disliked and of not getting help if they spoke candidly. One person stated:

It can be that you try to be nice out of fear. That you lose your contact if you are displeased or irritated. ...One suppresses these feelings because one is in a state of dependence. We suppress an aspect of ourselves to be nice and compliant and get the care and support needed (SU3).

Applying the framework of epistemic injustice, such strategies can be understood as testimonial smothering, i.e. speakers 'edit' communication in order to come through with their message or to avoid negative consequences. Expressing ideas and preferences in a straightforward manner was noted to entail the risk of being labeled as a "difficult or provocative" patient (SU17). In describing these strategies of curtailing communication service users maintained that such behavior might cause some information loss, information that might be vital in making sound assessments and decision-making processes.
Service Users Being Silent or Editing Testimonies: Staff Perspectives

Many providers discussed service users' incapacity or low motivation as obstacles to specific issues related to the legitimation of user knowledge. Some noted the difficulties in prompting service users to speak. This silence was interpreted as a lack of willingness to be an active participator.

You sometimes have to almost pull it out of them. What do you want? What do you think? How would you like...? Everybody does not talk so much spontaneously. And then... it doesn't always come naturally from them, but it's like they expect and want you to decide (P9).

Other providers, however, acknowledged the dependency service users experienced and related their silence and editing to such exposedness. Some providers asserted that including the experiential knowledge of service users was crucial for wellfounded decision making, and expressed concern that service users tend to modify their accounts and responses to correspond with what they believe the providers want to hear. Similarly, some providers acknowledged how during appointments with doctors service users were inclined to hold back from expressing their concerns and preferences because of feelings of insecurity when confronting an authority figure and how such silence might be interpreted as an unwillingness to participate in the decision process. Providers also observed how traditional psychiatric care throughout the years has posed role expectations on service users that favored passivity and compliancy, and how this current switch to expecting user involvement requires fundamental changes in the attitudes and habits of both service users and providers. As described by one provider, "They have been conditioned into being passive for many years and now suddenly they are requested to be active participators" (P11).

Participant Based Injustice: Not Inviting/Being Invited as Collaborators

Being Disregarded as Epistemic Collaborators: User Perspectives

The category being disregarded as epistemic collaborators was constructed based on service users' 
statements of not being invited as full collaborators as well as of providers' statements related to excluding service users from deliberative epistemic practices. As the category name suggests, these grievances from the excluded group can be understood as participantbased injustice, a concept that establishes how epistemic justice requires not only that a person's testimonies are assessed as being credible but also that the person is acknowledged as a knowledge gatherer, inquirer, problem-solver and decision maker [13].

The needs of service users as regards participation in SDM often concerned collaborative dialogical practices (e.g., having access to the agenda before meetings, being able to add issues to the agenda and discuss information collected by both parties from different sources and to review the same notations on what had been discussed and decided). Indeed, some service users referred to positive experiences of being included in deliberative practices such as being invited to co-reviewing and modifying providers' notations and co-writing doctor statements for sickness compensation. For the most part, however, service users expressed how these equal terms features of full transparency and collaboration were largely lacking in interactions. Many noted, for example, how bringing up ideas and questions on information they had gathered from peers or online often seemed to be perceived as "challenging" by the provider (SU6). One service user describes doctors' attitudes as assertive an overbearing, "I'm the doctor here. You should not make the diagnosis" (SU7). Some noted that having their inquiries thus disregarded left them feeling uncertain and wondering. In discussing information-gathering practices service users acknowledged the risks and pitfalls involved in online research and the sharing of anecdotal information. However, what was noted as lacking was the experience of feeling invited to raise questions about such information and to be met with openness, reasoning and clarification instead of dismissal.

Service users often described being excluded from deliberative conversations and decision making. They reported on incidences in which the staff members have already made up their mind before the meeting with the user. Similarly, service users recounted group meetings in which they were asked to leave the room at the end of the session so that the providers could deliberate and reach decisions on their own.
One user described the experience of being left out from decision making:

When the staff group has decided how it's going to be, their like "now you have gotten the help that you need" ...I didn't have any influence whatsoever. "Please don't think and have opinions! Our work routines direct what is to be done. You don't have to consider anything further. If you have further considerations, do not come to us" (SU10).

\section{Disinclination to Invite Service Users in Collaborative Practice: Staff Perspectives}

Service providers often referred to the importance of carefully listening to service users' reports, both to pinpoint the best course of action and for therapeutic, partnership and alliance-building effects. However, some of the same provider-respondents explicitly stated that the provider typically knows best on how to evaluate the information and reach a conclusion on the best course of action. According to them, information sharing with the service users needs to be strategically selective with the intent to motivate the users to follow the option preferred by the service providers. One provider described how he considers how much information is appropriate to share with the service user in a certain decision-making situation: "What information do I have and what information do I consider necessary for the person to receive to think, 'yes, I will go with this option" (P22). Another provider declared how making people feel "listened to and appreciated" makes them easier to control. ... So, it is a good tactic to increase compliance ... if we may be cynical" (P30).

Such strategies were motivated by the concern of safeguarding service users who, according to these providers, were prone to information overload or to make self-destructive choices. Involving service users in deliberative practices was considered to entail adding responsibility of uncertain outcomes on already vulnerable individuals. Some providers pointed to the complications involved when service users' consult peers or search the Internet. Again, such concerns related to the problems it might evoke for the service user. To process and relate to several sources of information were thought to be challenging to service users who risked being led astray and confused by misleading or irrelevant information. 
Some described how, in certain services, assessments of needs and benefits are strongly conditioned by regulations. Inviting service users in deliberative practices to express their own assessments of their needs and preferences might inadvertently signal "promising more than you can keep" (P2).

Even if many providers wanted to invite service users to take a more active role in collaborative practices, they often mentioned structural obstacles for not doing so. It was intimated, for example, how time limitations made it impracticable to listen to everything the service users wants to share. Some providers described the pressure on service users to have to navigate through fragmented, inflexible systems, where they had to repeat their situation to multiple staff.

According to some service providers, the challenges of handling these epistemic complexities was sometimes attributed to the lowered emotional and cognitive capacities of the mental health service users. Other providers, however, noted how finding your way through "jungles of plans, information and regulations" (P3) would be most challenging for any person. In addition, the prospect of knowing what one truly wants based on one's own values was considered a universal human challenge, especially in the face of important health decisions. As one provider stated, "What one thinks one day may prove unacceptable the next" (P28).

\section{Hermeneutical Injustice}

\section{Poorly Fitting Formats for Accounts and Frames for Interpretations: User Perspectives}

Carel and Kidd [24] conceptualize the phenomenon of practice-related conditions that hinder people from delivering information as a specific form of testimonial injustice. Accordingly, many users noted how important aspects of their life stories, social lives and strengths and weaknesses remained unexpressed or were lost in communication because time conditions and formats to collect information did not allow for such testimonies. In the early stages of analysis and in accordance with Carel and Kidd, comments on structural barriers were tentatively sorted under the main category of testimonial injustice. Upon closer examination, however, it became clear that the comments on such barriers were most often related to the frames of interpretation operating within the system. Because interpretive practice underlies formats and practices for information gathering, the hermeneutical dimension of this lack of formats to collect peoples' testimonies in the way that they wish is of interest for this category. Moreover, the poorly fitting formats to collect testimonies and the poor fit regarding frames for interpretations were tentatively formulated to constitute two separate categories. However, further data analysis suggested that formats for accounts and frames of interpretations proved to be inevitably linked.

Reports from service users indicated that organizational structures were designed for diagnostic, symptom-focused practices that did not seek nor allow for holistic perspectives for personal narratives or reflection. In the interviews service users often mentioned time constraints, lack of continuity and disjointed organizations as barriers for the interpretations they themselves made of their own experience to be neither expressed nor considered. On several occasions, service users reported that the disposition of professionals to view them through diagnostic frames of interpretation made them feel perceived as "an object" (SU4, SU10), rather than as a "whole human being" (SU4) or "not as a human being" at all (SU7). Some users noted that the favored interpretations of professionals always had precedence over their own understandings of the situation.

Service users expressed that the staff seldom showed interest in "the human being" (SU4) and the story and context of the person, or of the person's own understanding of his or her illness experience or of "the story behind" the current situation (SU19). Instead, as one person described it, "they ask the questions needed to make a diagnosis" (SU13). Service users often allude to their desire that providers were more interested in eliciting their views and their interpretations of their own situation and needs, and that opportunity were offered to ponder, reflect and give voice to their perspectives. Some users reported how they would like to bring a friend or relative who knows them and their illness history. One person noted that coming alone and in a state of ill-being resulted in practitioners viewing them as "just a user" and "that you are a human being with a life with friends and a history gets lost. You just become an object" (SU10). Furthermore, service users remarked about the inability of professionals to handle service users who had 
more than one diagnosis. The users described that teams specializing in specific diagnoses were not willing to communicate with each other. One user felt it would be "helpful for decision making" if the staff "could be more open to see several things at once, i.e. to see 'the whole' and cooperate with other teams and services" (SU12).

One user noted that the emphasis on "symptoms and journals" makes her "become ill just by constantly thinking 'ill'" (SU15). In response to this focus on illness and deficiencies, service users expressed hopedthat the staff would enquire about their strengths and what they as users could do to feel better and manage their illness. In that way they thought that they could "get support in the treatment" and at the same time be reminded about their "strengths and goals in life" (SU5).

In view of these comments from service users, it can be perceived how failing to adopt a holistic view and embrace personal narratives relating to personal recovery might not only be psychologically harmful but also counteract recovery orientation and wellgrounded decision making.

\section{Lack of Control Over Interpretations: User Perspectives}

Some service users noted how, in accordance with outmoded medical models, their illness was conceptualized as "chronic" and how lack of knowledge of recovery caused outdated labels of illness and dysfunction to be stuck on them and follow along in providers' understanding of them. One service user sensed that providers assume that certain diagnoses "are permanent" (SU22). Another user discerned that having had a psychiatric problem caused providers to regard them "in terms of your psychiatric history" for the rest of their lives (SU19). This same person noted how the staff might "bring up issues from 15-20 years ago", which have nothing to do with his current problems. He proposed that looking into documentation notes so far back in time is a praxis distinctive for the context of psychiatry and how this practice causes providers to miss relevant input by not "valuating the person who is sitting in front of them right now."

Being misinterpreted and having little or no control over how their difficulties are conceptualized, categorized and documented was expressed as frustrating and detrimental to joint deliberation. Service users expressed how powerless and exposed they felt because of the provider's lack of recovery knowledge in combination with the providers' jurisdiction over documentation. Words such as "horrible" and "scary" were used to describe these experiences. Some users claimed that professionals are inclined to interpret every behavior in psychiatric terms and that they were unable to defend themselves from this interpretive prerogative. As one user proclaimed, "if you stumble in the corridor, it will be recorded in your journal" (SU14).

As described in the passages above, the prevalent diagnostic practices and symptom-focused frames of interpretation were perceived by many service users as barriers to communication and for providers to consider areas of experiences that would be important to include in epistemic deliberations. In contrast, one service user related to experiences when too strong a reliance on social models of understanding mental illness proved just as detrimental as did reliance on medical models. She described how her recurring depressions had been conceptualized by general practitioners as a natural response to her stressful family situation, something that delayed the referral to psychiatric care and caused her to live with an undiagnosed bipolar disorder for many years.

\section{Not Accessing Hermeneutical Resources: User Perspectives}

Having shared modes of interpretation (e.g., concepts, ideas, narratives) available to frame, interpret and communicate significant aspects of our experiences is crucial to our social life [6]. The category not sharing hermeneutical resources pertains to service users' lack of linguistic or conceptual tools to articulate or understand their experiences or to comprehend what they are told about their condition. Many of the service users commented on their difficulties to understand the psychiatric terminology of the providers, wishing that a more ordinary language could be used. Some service users' mentioned the difficulties to grasp and convey their psychological problems, as these problems were often too diffuse and vague. This lack of ability to understand and explain relevant aspects of their situation was noted as a source of frustration, stress and disempowerment.

In contrast, medical definitions and modes of explanations were expressed by some users as vital for well-grounded decision making. These concepts 
were noted to increase thier understanding of their condition and thereby their manageability. The conceptual and therapeutic scope of medicine thus added to their hermeneutical resources by providing the tools they needed to comprehend and to explain their condition to relatives. For instance, one user remarked that the national online care guide (a service delivered by Sweden's county councils and regions) provided her with a plain and comprehensible list of all symptoms and with coherent information that she could easily pass on to her relatives. Another user said, "since I got my diagnosis, I am more aware. I recognize early signs” (SU23).

\section{Restricted Outlets for Narratives: Staff Perspectives}

Some providers recognized the hermeneutical disadvantage service users might experience from not having the linguistic tools to comprehend or express their condition. Many providers acknowledged that the formats offered to service users did not fit the ways in which service users wanted to deliver their testimonies. Some providers reported that they needed more time to listen to the service users' narratives and some recognized how the fragmented systems of highly specialized services led to a failure to perceive and treat people in a holistic manner looking at all aspects of their life. For example, they acknowledged the potential value of inviting and encouraging service users to think about what issues they want to discuss, questions they may have and what needs, preferences and goals they have in relation to their illness management and life in general. However, although they felt that such a process would provide a more holistic view of the user, they expressed that time limitations prevented such processes from occurring. One provider described this challenge as follows: "When will I have time to read what the patients have written? It feels like you don't really have time to sit with this before you see the patient" (P10). Providers often described how these structural barriers impeded their ability to engage in careful deliberation and SDM and placed considerable stress on the staff.

\section{Discussion}

In accordance with the aim of the study, analyzing service users and providers' narratives collectively helped to elucidate the epistemic mechanisms at work in interactions between these groups and identify barriers preventing legitimizing the knowledge of service users in deliberation and decision making. Both groups perceived how mental health service users were often exposed to epistemic challenges. However, even if the service users and providers described similar issues, they usually understood these issues differently. In describing obstacles preventing active participation in knowledge processes, service users indicated relational issues with the staff (e.g., dependent and exposed, dismissed and misinterpreted, excluded from collaboration and choosing to be silent or edit the communication). Service providers typically discussed workflow issues and service users' lack of decision-making competence and determination as well as vulnerability to stress factors (e.g., information overload, expectations of proactivity, navigating complex systems).

\section{Unawareness of Power Differentials Hindering Collaboration}

Consistent with previous analyses of epistemic power differentials in health services the current findings show that the professional community possesses epistemic privileges. For example, Carel and Kid [24] highlight the privilege of staff as acting as gatekeepers, of controlling which persons should be included in decision-making processes, deciding the degree of credibility and authority that should be ascribed to the various input, and ultimately, the power of decision, all of which are reflected in the providers and service users' own reports. Being subjected to epistemic domination was a theme observed in the users' perspectives. In accordance with the observation of Carver et al. [6], service users described how their personal testimonies were conceived as "sites of power struggles of status" [6, p50].

While many of the service users appeared to be aware of the power differentials in the mental healthcare system, the perceptions of the staff seemed more diverse. Although some providers noted these asymmetries, others described the exposedness of service users more in terms of a cumbersome organizational infrastructure and recognized how navigating these systems often posed unreasonably high demands on a group of service users with a generally lowered epistemic competency. In the literature on epistemic 
injustice such lack of awareness of the dominant group as to the power dynamics at work in the systems in which they operate is referred to as epistemology of ignorance. For members of the dominant group seeking to understand the experiences of members of a non-dominant group, the acknowledgement of power differentials is essential given that unawareness of power may mask important aspects of these experiences [25].

The majority of service users were members of user panels with experience in analyzing and evaluating mental health service. Conceivably, their strong awareness of power differentials in decision-making processes might be a result of such experience. They can be assumed to be empowered by having gained access to hermeneutical tools by analytical training, so that they are able perceive and verbalize the epistemic injustices that they are subjected to and thus having better means to counteract these inequalities. In contrast, service users who do not have the readiness to express feelings of powerlessness may not even be aware that there is a lack of participation with which to be frustrated. This unawareness might thus be perceived as an expression of hermeneutical injustice of which the epistemology of ignorance also prevails among the non-dominant group.

Being unaware as regards aspects of power associated with the role of service providers has previously been reported by Skau [26]. She reasons that lack of awareness might result in providers misinterpreting behaviors of service users. For instance, such behaviors as being reserved or quiet might be interpreted as unwillingness or complacency when in truth they are a manifestation of feeling exposed and powerless. Indeed, the present analysis showed that both providers and service users observed how the latter were sometimes apt to stay silent or to edit their testimonies, i.e. purposely curtailing their communication in meetings with providers. As shown in the analysis, user silence or editing while meeting with an authority figure may be the manifestation of a number of mechanisms identified in the framework of epistemic injustice. For example, the risk of potential testimonial dismissal may cause a service user to stay silent. In line with previous studies our findings show that providers need to be aware that cumulative actions of silencing or trusting may affect later interactions (e.g., a service user withdraws and avoids communication) [24]. Munroe [27] draws attention to the prescriptive function of testimonial injustice, noting how a speaker can be assigned with what he labels prescriptive credibility deficits. This occurs when there is a risk of a person being punished if behaving in a counter-stereotypic way, as, for example, when a service user is assigned less credibility or likeability as a consequence of acting in an overly assertive manner.

A provider intent on listening to a service user might thus be ignorant that relevant information might not be expressed or circumscribed because of the users' earlier experiences of not being ascribed credibility. Moreover, from the providers' perspective, who perceive themselves as attentive listeners to the reports of service users, the current analysis indicates how a commitment to listening may obscure the oversight of not inviting service users to be full partners in shared inquiry, deliberation and decision making. Providers may acknowledge the views of the service users as important because they provide knowledge on the users' perspectives on their situation. However, even if service users are encouraged to share their views, this does not necessarily imply that they have any influence or control over how this knowledge is applied in decision making. Conversely, a key tenet of SDM is that service user views have actual influence over decisions [28]. Consequently, providers who mistake listening for collaborating might see themselves as attentive while the service user feels excluded and ignored. Carel and Kidd [24] in their study of epistemic injustice in health care designate how patients are commonly regarded as valuable informants but that practitioners hold the license to analyze, interpret and act on the information that is shared.

Additional to the obstructions for person-centered decision making that occur by not having both parties be invited and trusted as full partners in the collaborative practices of pooling and assessing information, the consequences of such exclusion might, as suggested in the analysis, be understood as participantbased injustice. Although the users' testimony is believed, not being regarded as full epistemic subjects might be experienced as epistemic objectification, something that, according to Fricker [9], might cause harm, both to their psychological state and to their 
practical life. Moreover, not being full epistemic subjects might have a silencing effect $[9,15]$.

Being Protective of Vulnerable Individuals with Low Epistemic Competency

Providers often described how they took a protective stance, shielding service users from the confusion, uncertainty and anxiety that can be caused by information overload and multiple options. Furthermore, providers reported that they encouraged service users to understand what they needed and the preferred outcomes. Ramon et al. [4] draws attention to this tendency to be protective, noting how decisions that are weighted towards risk or safety concerns may place limitations on SDM and on user involvement in decisions. In many cases the choices from which to decide is often unilaterally defined by practitioners who may steer service users towards a particular decision or mark a course of action as best [4, 29]. The difficulty of weighing conflicting values was manifested in some of the service providers' comments. The benefits in lending service users the autonomy entailed in being a full partner in epistemic practices was balanced against the risk of burdening a vulnerable group with added responsibilities.

Service users frequently observed practitioners devaluing their testimonies by arguing that the users had lowered epistemic capacity associated with their mental illness. Of course, psychiatric ailments may reduce epistemic competency, especially during periods of acute illness. However, as was confirmed by many service users, professionals generally characterized users in terms of permanent extensive irrationality and cognitive deficits, causing epistemic injustice. A stance of habitually dismissing user accounts as largely delusional deprives service users from epistemic agency and might obscure the truth in cases in which their spoken or written communication warrants credibility and attention.

Particularly noteworthy is that service users sometimes felt they were not being treated as a human being. These statements might be viewed from Fricker's notion of testimonial injustice and her point that the capacity to give knowledge and to be taken seriously as an informant is central to reason and rationality, which are crucial elements of the selfimage of human beings. Consequently, being devalued as inferior and inconsequential could be experienced as being disqualified as a human being [9, 15]. As such, being disregarded as someone with knowledge might imply an added layer of damage to the epistemic harm in that it also bears a social meaning of dehumanization [9].

Diagnostic Frameworks: the Power of Categorization

The cognitive handicap involved in not having the hermeneutical resources necessary for conveying personal experiences has been described in several papers on hermeneutical injustice, some analyzing health care in general and some addressing mental health contexts in particular. A key tenet of hermeneutic philosophy is the notion of language being the vehicle by which understanding can be created and the principal means of sharing complex human experiences. Carel and Kidd [24] suggest that hermeneutical practices play an important role in health care because they allow service users sense-making reflectivity, which helps to turn a confusing and troubling set of symptoms into a more comprehensible and tenable context. As highlighted by Kurs and Grinshpoon [30], an excessive use of medical or academic discourse might jeopardize service users' recovery by alienating and silencing them, leading to a loss of confidence in their ability to communicate.

In contrast, the analysis also revealed instances in which medical terminology (e.g., referring to diagnoses and symptoms) added to service users' hermeneutical resources of interpreting and communicating their experiences. In an examination of the case of medicalization in light of epistemic injustice theory Wardrope shows the complexities involved in this matter and how taking issue either for or against medicalized models of phenomena may be equally unconstructive. Certainly, service users in the present study reported how medicalized descriptions were often incorrect or incomplete and how they may obscure and distort our understandings of experiences and conditions. It should be noted, however, that some comments resonated with the point made by Wardrope [31] who asserts how criticism of such descriptions may indeed silence the voices of some service users "for whom medicalization may prove to illuminate, not cloud, experience - and rather than undermining their ability to cope ... affords them with strategies by which to do so." (p. 352). Thus, the present findings 
support providing service users with clear and comprehensible information as part of the SDM process, which makes medical terminology coherent and accessible.

In the phase of implementation and evaluation of the SDM program providers often referred to structural barriers as a core issue preventing inviting service users from participating as full epistemic subjects [17]. Having to constantly deal with emergency situations and lacking the time and resources necessary to listen to users' narratives and for interprofessional collaboration that would be needed to view and support people in a holistic way was a source of immense frustration.

While recognizing the obstacles to SDM caused by these structural barriers and acknowledging the need for redesigning systems to create adequate conditions for SDM, it is worth mentioning that some studies emphasize how barriers to new working methods might be linked to beliefs and norms and how they nurture habitual procedures. It seems that the staff is often unaware that their thinking and acting are directed by certain sets of assumptions [32, 33]. Carel and Kidd [24] point out how care and support practice is grounded in norms for evidence and for epistemic exchanges and privileges, as well as ways of articulating experiences and sharing knowledge. It could be discerned, by the findings of the current study, how a still dominant medical system of beliefs and norms about what it means to be service users of mental health services and what needs to be done to solve problems is reflected in both the professional and service user's perceptions of the latter's ability to participate and contribute with input in decisionmaking processes. Numerous authors have observed how these basic assumptions at work in a welfare organization are linked to the power position of the professional [32] as an official 'troubleshooter' and mediator in determining the nature of the problem [34]. Problems are defined based on assumptions, theories and power balances [34], which do not necessarily correspond to an individual's perception of the problem [35]. The present analysis delineates service users' powerlessness in face of what was documented and how specific particulars (e.g., journal notes) biased professionals' perceptions of their predicaments. The literature suggests that providers might not be aware of the power embedded in their authority to classify and categorize but that they might be prone to believe that they are simply reporting when in fact they are constructing [36].

Including service users' descriptions of their problems is therefore important to access and generate knowledge whereby the perspectives of service users are allowed to impact on how phenomena can be perceived, categorized and described [37]. According to the service users' perspectives in the present study, this might be achieved by engaging service users in SDM from the start of the decision-making process so that they are allowed to participate in the initial problem analysis of their situation.

Moreover, the current analysis revealed how service users often lacked the vocabulary to grasp and express their experiences, illustrating their need for greater access to medical terminology as well as conceptual tools for describing the psychosocial and existential features of their illness. These findings underscore how hermeneutical injustice may be ameliorated by providing comprehensible medical information as well as by using and validating philosophical, emotive and idiosyncratic terminology that might support the service user in interpreting and articulating his or her illness experiences [24].

\section{Conclusions}

Knowledge from implementation science suggests that staff personnel need to see the benefits to service users in order to embrace a new way of working [38]. When new working methods implicate conflicting values, the risk of doing more harm than good may dispose staff members to adhere to their traditional practice. In acknowledgement of such concerns, criticism is sometimes voiced that the prospect of involving service users as full epistemic subjects in SDM fails to capture issues related to professional accountability and the complexities involved in sharing risk and responsibility with service users [39, 40]. To counteract such reluctance, the providers need to be informed about the value of autonomy and epistemic justice. The current analysis demonstrates how the extent of agency granted to speakers is regulated by the ways in which their testimony is heard, taken into consideration and acted upon by the recipient [6]. It has served to identify some specifics of what it actually means to service users to be excluded as well as what it means to be regarded as a worthy 
interlocutor and collaborator. Indeed, such knowledge might inspire practitioners to move from an overly protective style towards a greater optimism as regards service users' competence and determination. As suggested by previous analyses promoting epistemic justice in healthcare contexts, the present study confirms that providers might strive towards a disposition of epistemic humility and reflexive awareness in relation to their own assumptions, credibility judgments and interpretive habits, in order to become more open to service users' interpretations and regard these as vital contributions to knowledge generation and problem analysis [10, 24, 41]. Notably, during the course of the current SDM project, it became evident that such reflexivity was stimulated among providers when they were involved in the development of support for SDM and by practicing SDM in a formalized manner [16, 17]. In agreement with previous literature, it was noted that applying the consecutive steps in the SDM process relative to their own practice often promoted more honest assessments among providers of their own habitual attitudes and behaviors and revealed new possibilities for involving service users as epistemic subjects [3, 42].

In accordance, becoming aware of the biases that might be linked to the interpretive prerogative of professionals and understanding the powerlessness service users might experience as a result of these biases, providers might become favorably disposed to involve service users in the epistemic practices such as problem analysis and documentation. By actively and systematically requesting and legitimizing service users' knowledge perspectives and inviting service users to have greater epistemic roles in collaborative decision making, greater levels of epistemic justice may therefore be achieved.

The epistemic authority of trained professionals for various conditions may often be appropriate and warranted. However, while the existence of justified epistemic asymmetries should not be denied, such asymmetry might be compatible with dialogic partnership, respectfulness and open information exchange [24]. Sanati and Kyratsous [11] suggest that providers need to make their credibility judgements of mental health service users more nuanced and graded and to avoid dismissing service users' testimonies without thorough examination of their trustworthiness.

From the present findings, it is evident that the issues identified as obstacles for service users to be full deliberative collaborators in decision processes (i.e. as knowledge seekers, knowledge bearers and problem solvers) need to be addressed in order to be able to practice mental health care that is truly person centered. Our findings indicate that a fruitful way to overcome these barriers would be to apply SDM processes in which service users are engaged in the formulation of the agenda before meetings, as cowriters of plans for treatment, goals or service coordination and as co-reviewers and editors of what is documented.

\section{Methodological Considerations}

Because comments from service users comprised most of the data (approximately 70 percent), a disproportionate part of the categories is made up service user perspectives. Hence, a potential risk for bias in the analysis might result from this imbalance. Still, despite this risk, a collated analysis of these datasets was found to generate relevant insights into the subject matter. In addition, the focus of inquiry concerned barriers for SDM and needs for decision support. Accordingly, participant comments were mainly related to difficulties and problems. For the present study, this circumstance provided an analysis in which negative and problematic issues were illuminated to a greater extent than positive experiences, a fact that might give a disproportionately negative characterization of peoples' experiences of decision-making processes.

\section{Suggestions for Future Research}

The current analysis was performed on data collected to develop and implement SDM, i.e. to support the acknowledgement and inclusion of user knowledge in decision-making processes regarding the care and support of service users on the individual level. A theoretic scrutiny of the dynamics at work in the domains of epistemology and agency may be equally relevant for studies investigating knowledge processes at organizational and systemic levels. Such an undertaking might involve interventions in which service users are engaged as knowledge bearers in patient education, as peer supporters or when involved in 
knowledge production such as in the development and dissemination of policy documents and guidelines.

Acknowledgements Open access funding provided by Dalarna University.

Open Access This article is distributed under the terms of the Creative Commons Attribution 4.0 International License (http:// creativecommons.org/licenses/by/4.0/), which permits unrestricted use, distribution, and reproduction in any medium, provided you give appropriate credit to the original author(s) and the source, provide a link to the Creative Commons license, and indicate if changes were made.

Funding The funding was provided by Forte Grant No. (201404489).

\section{References}

1. Stovell D, Morrison AP, Panayiotou M, Hutton P. Shared treatment decision-making and empowerment-related outcomes in psychosis: systematic review and meta-analysis. Br J Psychiatry. 2016;209(1):23-8.

2. Goscha R, Rapp C. Exploring the experiences of client involvement in medication decisions using a shared decision making model: results of a qualitative study. Community Ment Health J. 2015;51(3):267-74.

3. Morant N, Kaminskiy E, Ramon S. Shared decision making for psychiatric medication management: beyond the microsocial. Health Expect. 2015;19(5):1002-14.

4. Ramon S, Brooks H, Rae S, O'Sullivan M-J. Key issues in the process of implementing shared decision making (DM) in mental health practice. Ment Health Rev. 2017;22(3):257-74.

5. Slade M. Personal recovery and mental illness: a guide for mental health professionals. Cambridge: Cambridge University Press; 2009.

6. Carver L, Morley S, Taylor P. Voices of deficit: mental health, criminal victimization, and epistemic injustice. Illn Crisis Loss. 2017;25(1):43-62.

7. Stacey G, Felton A, Morgan A, Stickley T, Willis M, Diamond $\mathrm{B}$, et al. A critical narrative analysis of shared decision-making in acute inpatient mental health care. J Interprof Care. 2016;30(1):35-41.

8. Manley K, McCormack B. Practice development: purpose, methodology, facilitation and evaluation. Nurs Crit Care. 2003;8(1):22-9.

9. Fricker M. Epistemic injustice: power and the ethics of knowing. Oxford: Oxford University Press; 2007.

10. Crichton P, Carel H, Kidd IJ. Epistemic injustice in psychiatry. BJPsych Bull. 2017;41(2):65-70.

11. Sanati A, Kyratsous M. Epistemic injustice in assessment of delusions. J Eval Clin Pract. 2015;21(3):479-85.

12. Anderson DE. Conceptual competence injustice. Soc Epistemol. 2017;31(2):210-23.

13. Hookway C. Some varieties of epistemic injustice: reflections on Fricker. Episteme. 2010;7(2):151-63.
14. Pohlhaus G Jr. Varieties of epistemic injustice. The Routledge handbook of epistemic injustice. London: Routledge; 2017. p. 31-44.

15. Kwong JM. Epistemic Injustice and Open-Mindedness. Hypatia. 2015;30(2):337-51.

16. Grim K, Rosenberg D, Svedberg P, Schön U-K. Development and usability testing of a web-based decision support for users and health professionals in psychiatric services. Psychiatr Rehabil J. 2017;40(3):293-302.

17. Schön U-K, Grim K, Wallin L, Rosenberg D, Svedberg P. Psychiatric service staff perceptions of implementing a shared decision-making tool: a process evaluation study. Int J Qual Stud Health Well-being. 2018;13(1):1-12.

18. Grim K, Rosenberg D, Svedberg P, Schön U-K. Shared decision-making in mental health care: a user perspective on decisional needs in community-based services. Int J Qual Stud Health Well-being. 2016;11:1-8.

19. Kaminskiy E. The Elephant in the room: a theoretical examination of power for shared decision making in psychiatric medication management. Intersect Glob J Soc Work Anal Res Polity Pract. 2015;4(2):19-38.

20. Graneheim UH, Lindgren B-M, Lundman B. Methodological challenges in qualitative content analysis: a discussion paper. Nurse Educ Today. 2017;56:29-34.

21. Layder D. Sociological practice: linking theory and social research. London: Sage; 1998.

22. Elo S, Kyngäs $H$. The qualitative content analysis process. J Adv Nurs. 2008;62(1):107-15.

23. Erlingsson C, Brysiewicz P. A hands-on guide to doing content analysis. Afr J Emerg Med. 2017;7(3):93-9.

24. Carel H, Kidd IJ. Epistemic injustice in healthcare: a philosophial analysis. Med Health Care Philos. 2014;17(4):529-40.

25. McKinnon R. Epistemic injustice. Philosophy Compass. 2016;11(8):437-46.

26. Skau GM. Mellan makt och hjälp. Stockholm: Liber; 2007.

27. Munroe W. Testimonial injustice and prescriptive credibility deficits. Can J Philos. 2016;46(6):924-47.

28. Treichler EB, Spaulding WD. Beyond shared decisionmaking: collaboration in the age of recovery from serious mental illness. Am J Orthopsychiatry. 2017;87(5):567-74.

29. Quirk A, Chaplin R, Lelliott P, Seale C. How pressure is applied in shared decisions about antipsychotic medication: a conversation analytic study of psychiatric outpatient consultations. Sociol Health Illn. 2012;34(1):95-113.

30. Kurs R, Grinshpoon A. Vulnerability of individuals with mental disorders to epistemic injustice in both clinical and social domains. Ethics Behav. 2018;28(4):336-46.

31. Wardrope A. Medicalization and epistemic injustice. Med Health Care Philos. 2015;18(3):341-52.

32. Järvinen M. Mötet mellan klient och system-om forskning i socialt arbete. Dansk Sociologi. 2006;13(2):73-84.

33. Smith K. Reflection and person-centredness in practice development. IPDJ. 2016;6(1):1-6.

34. Emerson RM, Messinger SL. The micro-politics of trouble. Soc Probl. 1977;25(2):121-34.

35. Bourgois P. Disciplining addictions: the bio-politics of methadone and heroin in the United States. Cult Med Psychiatry. 2000;24(2):165-95.

36. Holstein JA. Producing people: descriptive practice in human service work. Curr Res Occup Prof. 1992;7:23-39. 
37. Svensson K, Johnsson E, Laanemets L. Handlingsutrymme: utmaningar i socialt arbete. Stockholm: Natur och kultur; 2008.

38. Nilsen P. Implementering av evidensbaserad praktik. Lund: Gleerups Utbildning; 2014.

39. Hamann J, Heres S. Adapting shared decision making for individuals with severe mental illness. Psychiatr Serv. 2014;65(12):1483-6.

40. Légaré F, Ratté S, Gravel K, Graham ID. Barriers and facilitators to implementing shared decision-making in clinical practice: update of a systematic review of health professionals' perceptions. Patient Educ Couns. 2008;73(3):526-35.
41. Buchman DZ, Ho A, Goldberg DS. Investigating trust, expertise, and epistemic injustice in chronic pain. J Bioeth Inq. 2017;14(1):31-42.

42. Matthias MS, Salyers MP, Rollins AL, Frankel RM. Decision making in recovery-oriented mental health care. Psychiatr Rehabil J. 2012;35(4):305.

Publisher's Note Springer Nature remains neutral with regard to jurisdictional claims in published maps and institutional affiliations. 